\title{
Los desafíos del sorteo a la democracia, los desafíos de la democracia al sorteo*
}

\author{
The Challenges of Sortition to Democracy, the Challenges of \\ Democracy to Sortition
}

\author{
JOSÉ LUIS MORENO PESTAÑA**
}

\begin{abstract}
Resumen: En este artículo se estudian las contribuciones presentes en este monográfico. El texto explica, primero, cómo el sorteo nace de otro modo de abordar la tradición en historia de las ideas y las instituciones republicanas y democráticas. En segundo lugar, el artículo muestra, siempre con este número de la revista como referente, cómo el sorteo abre un nuevo campo de debates acerca de cómo profundizar nuestras prácticas democráticas.

Palabras clave: Sorteo, democracia, filosofía política, sociología política.
\end{abstract}

\begin{abstract}
In this article we study the contributions in this monographic journal issue. The text explains, first, how sortition is born from another way of approaching the tradition in the history of republican and democratic ideas and institutions. Second, the article shows, always with this issue of the magazine as a reference, how sortition opens a new field of debate about how to deepen our democratic practices.
\end{abstract}

Key words: Sortition, Democracy, Political Philosophy, Political Sociology.

\section{La reactivación de un elemento de la democracia}

Aunque al final del siglo XIX se conocieron exposiciones solventes del mecanismo del sorteo en el mundo antiguo ${ }^{1}$, hubo que esperar a la segunda mitad del pasado siglo para encontrarlo en los debates sobre la democracia. Fue fruto de varios espacios de conocimiento y de actividad política. Por un lado, el desarrollo de una historia de análisis de los procedimientos democráticos, lo cual supone despegarse del culto a los grandes nombres

Fecha de recepción: 31/08/2017. Fecha de aceptación: 20/09/2017.

* Texto escrito en el marco del proyecto de I+D: "La recepción de la Filosofía grecorromana en la Filosofía y las Ciencias Humanas en Francia y España desde 1980 hasta la actualidad” (FFI2014-53792-R). Quiero agradecer a Francisco Manuel Carballo Rodríguez, Jorge Costa Delgado, Liliane López-Rabatel, Julio Martínez-Cava Aguilar e Yves Sintomer la lectura y sugerencias para esta presentación.

** Profesor de Filosofía en la Universidad de Cádiz. Email: joseluis.moreno@uca.es. Investiga y publica sobre sociología de la filosofía y filosofía política. Sus dos últimos libros son La norma de la filosofía. La configuración del patrón filosófico español tras la Guerra Civil (Biblioteca Nueva, 2013) y La cara oscura del capital erótico. Capitalización del cuerpo y trastornos alimentarios (Akal, 2016).

1 El libro de James Wycliffe Headlam Election by lot at Athens, publicado por Cambridge University Press, es de 1891. 
de las humanidades y las letras. No sólo en lo que respecta al mundo griego clásico, donde el sorteo no jugaba el mismo papel en la democracia ateniense que en la de Siracusa ${ }^{2}$, sino también en las repúblicas del final de la Edad Media. Ese conocimiento especializado, y es un segundo paso, debe filtrarse a otros campos que trabajan sobre referencias históricas.

Pondré un ejemplo. Durante el I Congreso de la Red Española de Filosofía, celebrado entre el 3 y el 5 de setiembre de 2014 en Valencia, y dentro de un debate sobre la actualidad de Marx, alguien definió las dos líneas concurrentes en el movimiento político del $15 \mathrm{M}$ (y del naciente partido Podemos) como las que oponían Maquiavelo a Spinoza. El primero representaba, presuntamente, la conciencia estratégica mientras que el segundo defendería los movimientos sociales y la potencia de la multitud. (De hecho, Maquiavelo era alguien puesto de moda por el revival gramsciano-populista de los fundadores de Podemos, mientras que Spinoza remitía a la supuestamente más democrática corriente filosófica que encuentra sus galas entre Louis Althusser y Antonio Negri). Cabría haber argüido refiriéndose a los modelos políticos de ambos filósofos, sin duda interesantes para comprender cómo materializaban sus ideas. El primero pensó en el sorteo para frenar el apetito de los grandes - si seguimos a J. Mc Cormick - mientras que el segundo admiraba los sistemas aristocráticos que lo empleaban (así la Corona de Aragón o la serenísima República de Venecia) y propuso en su modelo aristocrático un Consejo de Cónsules que convocase al Senado y preparase su agenda (en lo que se perciben funciones del Consejo de los Quinientos en Atenas).

El problema no alude a defecto alguno de las personas que allí debatían, sino a un cierto modo de socialización intelectual en la historia de las ideas, donde a estas se les vacía del contexto y de los procedimientos que las encarnan. Maquiavelo y Spinoza, mirados a través del sorteo, enseñan mucho acerca de cómo la cultura republicana puede guarecerse de los apaños de los poderosos ${ }^{3}$. Lo mismo puede decirse de espacios intelectuales que trascienden el comentario de los clásicos. Así, los debates sobre la democracia deliberativa en donde emergió la figura de James Fishkin, cuya empresa (intelectual y económica), nos enseña Julien Talpin, tanta relevancia tiene para el uso del sorteo.

Esa transmisión desde la historia de la institución del sorteo a la filosofía y la sociología se ha acelerado en los últimos tiempos. Estrellas de lo que Perry Anderson llamó el marxismo occidental, como Fredric Jameson, recurren a Barbara Goodwin y su modelo radical de implementación del sorteo, en su reciente manifiesto utópico ${ }^{4}$. La obra de

2 La de Siracusa fue una democracia bastante más controlada por los demagogos, precisamente debido a la carencia de la Boulé o Consejo sorteado. Véanse las consideraciones en Ober, J. (2017): L'énigme grecque, París, La Découverte.

3 Mc Cormick, J. (2011): Machiavellian Democracy, Cambridge, Mass, Cambridge University Press, pp. 104105. Yves Sintomer me señala los problemas de la tesis, acerca del pensamiento de Maquiavelo, contenida en esta obra. Quede constancia de mi agradecimiento. En cualquier caso, la tendencia a separar la historia de las ideas de la historia de las instituciones sigue volviendo pertinente el ejemplo.

4 Jameson no se extiende sobre la cuestión, simplemente afirma que el sorteo sirve para eliminar las rapiñas de bienes y puestos que permiten las coaliciones de clase. Jameson remite al mundo griego pero su modelo, en el cual se distribuyen los empleos, hubiera encontrado difícil acogida en Atenas. De momento, contradice el relato legitimador del sorteo que construye Protágoras en el diálogo platónico homónimo. Los hombres son iguales en capacidades políticas, pero nunca en cualificaciones técnicas ya que adquirir una o algunas de ellas impide adquirir otras. Véase Jameson, F. (2017): An American Utopia. Dual Power and 
Goodwin propone el sorteo para asignar masivamente recursos. No sólo bienes escasos con exceso de demanda, algo normal entre nosotros (por ejemplo, cuando se sortean viviendas de protección oficial o candidatos a un tratamiento médico caro y escaso). Goodwin, y Jameson la sigue, propone asignar masivamente por sorteo los recursos económicos y los empleos. Se piense lo que se piense de tales propuestas, no son las que se discutirán en este número, excepto en un aspecto: el sorteo sirvió en la Atenas clásica para distribuir puestos políticos pero también recursos económicos mediante los salarios que se le asociaban. Enseguida me referiré a ello en esta presentación.

El vínculo del sorteo con el marxismo, en una tradición cuyo referente democrático es la democracia de consejos, tiene bastante de innovador ${ }^{5}$. Pese a lo cual, ya figuraba en la obra del helenista Arthur Rosenberg (reivindicada por Antoni Domènech) y en la obra de Kojin Karatani Transcritiques. On Kant and Marx (2003). A través de ella, la identificación del sorteo con instituciones anticapitalistas despertó el interés de Slavoj Zizek, quien en su reciente visita, en olor de multitudes, a España ha defendido las loterocracias ${ }^{6}$. En fin, desde otras coordenadas intelectuales y políticas el sorteo ha recibido igualmente atención. Erik Olin Wright incorporó la discusión de la "democracia aleatoria" (inspirada en los procedimientos deliberativos sorteados) dentro de su proyecto de una utopía socialista ajena al capitalismo y al estatismo ${ }^{7}$. En fin, como ha señalado Gil Delannoi, el sorteo no sirve solo a los defensores del igualitarismo político, también a los liberales inclinados a utilizarlo para garantizar la imparcialidad en los asuntos controvertidos ${ }^{8}$.

the Universal Army, Londres, Verso. El modelo de Barbara Goodwin (incluido en su libro de 1992 Justice by lottery) incluye la distribución aleatoria de opciones vitales (así, empleos para los que los individuos deberían formarse) una decena de veces a lo largo de una vida. Tal utopía podría pensarse como una suerte de experimento con una función específica: una sociedad por sorteo ayuda a ver cuánto se debe, en nuestras sociedades, a beneficios injustos de quienes acceden sistemáticamente a ciertos privilegios. El sorteo tiene algo de hipótesis sociológica radical: cómo sería una sociedad si en las distribuciones estadísticas de los individuos no funcionasen poderes no explícitos; el mérito podría seguir funcionando pues este podría servir para definir un censo de personas competentes para entrar en el sorteo. Véase la reflexión sobre la diferencia entre las distribuciones estadísticas constatadas (fuertemente desigualitarias) y las distribuciones estadísticas teóricas (que se obtendrían si determinadas variables no distribuyeran discriminatoriamente a los individuos) en Bourdieu, P. (2016): Sociologie générale. Volume 2. Cours au Collège de France 19831986, París, Seuil, pp. 691-692.

5 La democracia de consejos admite diferentes modelos, en la mayoría de los cuales debido a la fusión de órganos ejecutivos y legislativos faltan los controles y contrapesos que introducen las cámaras sorteadas. En Atenas, los poderes de organismos sorteados ayudaron a controlar las derivas demagógicas de las asambleas. En cualquier caso, una democracia de consejos acaba dando lugar, casi inevitablemente, a una aristocracia de hecho. Véase sobre las diferencias entre democracia de consejos y democracia por sorteo Luccardie, P. (2014): Democratic Extremism in Theory and Practice. All Power to the People, Nueva York, Routledge, pp. 85-87.

6 Véase Lorenci, M. (2017): “Zizek, un torbellino filosófico", La Verdad, 30/06/2017, http://www.laverdad.es/ sociedad/zizek-torbellino-filosofico-20170630014949-ntvo.html, consultado el 23/07/2017. Véase la lectura de Zizek de la obra, luego incorporada con matices en varias obras posteriores, en Zizek, S. (2004): "The parallax view", New Left Review, n ${ }^{\circ} 25$.

7 Véase el capítulo VI de su obra (original de 2010) Construyendo utopías reales, Madrid, Akal, 2014.

8 Delannoi, G. (2010): Le retour du tirage au sort en politique, París, Fondapol, pp. 33-34. La creación de un espacio público no faccioso no es exclusivamente liberal, aunque hoy sea un elemento distintivo de lo mejor de esa tradición. De hecho, de la rica y compleja historia de la insaculación en las Coronas de Aragón y de Castilla parece derivarse una cierta lógica antifacciosa - normalmente antinobiliaria - en su utilización a nivel municipal. Solo el sorteo permitió a los reyes de Aragón o a los Reyes Católicos controlar la manipula- 
Pero el sorteo no sólo se ha introducido en la literatura especializada, ya sea en aquella, fundamental, para comprender su papel histórico en la tradición democrática (o tal vez sea más preciso hablar de republicana), o en el pensamiento democrático. Ha aparecido como recurso de la movilización ciudadana. Durante las movilizaciones en la Plaza Sintagma de Atenas recurrieron al mismo para distribuir el tiempo de palabra ${ }^{9}$. En España, y en un proceso que comenzó también en la movilización ciudadana, ha acabado teniendo un sitio modesto pero real en el debate político. En las elecciones presidenciales francesas de 2017, el sorteo adquirió un papel de envergadura. Por citar algunas propuestas, el presidente electo Emmanuel Macron prometió un organismo sorteado que supervisase al presidente de la República, mientras que Benoît Hamon (candidato del Partido Socialista Francés) llevaba en su programa la introducción de ciudadanos sorteados en el Senado; en fin, Jean-Luc Mélenchon, candidato a la izquierda de Hamon, proponía una Asamblea Constituyente donde se participase por sorteo. Más radical, el partido político mexicano Morena seleccionó, para ciertos puestos institucionales, candidatos por sorteo.

\section{Sorteo, cultura técnica e imaginario histórico}

En esas coordenadas se escribe nuestro monográfico. Porque "Sorteo y democracia" contiene trabajos situados en la encrucijada de, al menos, tres grandes caminos. Por un lado, reflexiones filosóficas acerca del lugar del sorteo en la teoría de la democracia, por otro, una interrogación histórica sobre qué papel desempeñó ayer y cuánto puede ello enseñarnos acerca de cuál asignarle hoy; en fin, el presente especial de Daimon. Revista internacional de filosofía contiene además análisis de los usos políticos del sorteo, de cómo éste sirve para canalizar energías militantes por todo el mundo, con especial énfasis en las importantes movilizaciones ciudadanas de la presente década.

Aunque resulta importante aclarar algo. No se trata de que en este número los artículos puedan ordenarse desde una de esas perspectivas, aunque cada autor tienda a acentuar un ángulo determinado. No, lo importante de un número como este es que obliga a cada uno de los participantes a movilizar saberes en los tres planos.

La razón es sencilla. El sorteo identificó prácticas republicanas y democráticas en otras épocas; en la nuestra, su lugar no es inexistente y tiende a extenderse - con rasgos que se dilucidarán aquí-, pero sigue despertando desconfianza. Buena parte de ésta se apoya en un conocimiento histórico muy pobre el cual, en bastantes situaciones, confunde el razonamiento. En cualquier caso, sería ingenuo creer que basta con rescatar las potencialidades democráticas del sorteo para que las incorporen nuestras democracias. Cierto que tal empresa puede ser legítima. Algunos de los dispositivos ayer respondían a preguntas

ción nobiliaria de las elecciones. El sorteo es el garante de un espacio público relativamente independiente, allí donde existen muy poderosos capaces - y tendentes - a manipular los procesos electorales. Véase el detallado estudio de Polo Blanco, R. (2012): "Los Reyes Católicos y la insaculación en Castilla", Studia historica. Historia Medieval, vol. 17, pp. 137-199.

9 Véase Collectif Lieux Communs (2011): Le mouvement grec pour la démocratie directe. Le "mouvement de places” 2011 dans la crise mondiale. Première partie, p. 37, https://collectiflieuxcommuns.fr/IMG/pdf/ MouvementGrecDemocratieDierctPremierePartie.pdf, consultado el 22/06/2017. 
que aún son las nuestras. Para enfrentarse a ellas, a nuestras preguntas, nunca estorba comprender que la práctica del sorteo permitió encarnar institucionalmente ciertos ideales valiosos; estos, que aún celebramos, suelen ser maltratados por los funcionamientos de nuestras democracias. Así, el sorteo sigue ayudando a la democracia a profundizarse.

Ahora bien, la interrogación no circula en una única dirección. Yves Sintomer muestra en su trabajo la diferencia entre el sorteo de la democracia ateniense y el utilizado, por ejemplo, en los minipúblicos de deliberación, preguntándose cómo sería posible imaginar un sorteo - como el del gobierno ático - que distribuya masivamente, mediante participación y rotación rápida, competencias políticas a los ciudadanos. Sintomer considera que, dado el tamaño de nuestras comunidades políticas y los principios en los que se inspiran, el principio de gobernar y ser gobernado no acompaña nuestros usos del sorteo y seguirá sin hacerlo si no media un cambio radical en nuestro sistema político.

Nuestras prácticas democráticas también proponen interrogantes nuevos al sorteo. Hemos dejado de identificar sin más, como explica Sebastián Linares, sorteo y democracia, algo que puede derivarse de ciertas lecturas simplificadas del legado de la filosofía antigua, señaladamente de Aristóteles. El sorteo y la elección deben medirse alrededor de criterios que cualifican la calidad democrática de un proceso de distribución política de funciones. Esos criterios, nos recuerda Linares, incluyen la igualdad de trato entre los ciudadanos, la libertad de elegir y el valor epistémico que resulte del proceso de selección. Cuando comparamos elección y sorteo puede concentrarse el análisis en uno solo de los planos, obviando otros: quien atienda preferentemente a la igualdad de trato ensalzará las virtudes democráticas del sorteo, y algo muy distinto sucederá si encara el problema desde el punto de vista del resultado epistémico de la técnica democrática. Incluso en ese punto, Dimitri Courant lo apunta, cabe el debate pues no está nada claro si el sorteo selecciona a más incompetentes que la elección.

Resolvamos como sea tales debates, lo cierto es que debemos situar el sorteo dentro de entornos culturales más amplios, para que podamos comprender su papel. Sobre ello insistió con vigor la obra sobre la democracia antigua de Cornelius Castoriadis ${ }^{10} \mathrm{e}$ Yves Sintomer, en su artículo, precisa la cuestión en un punto tan sensible como el de la articulación entre la cultura técnica y la cultura política. Nuestra actividad cultural se desarrolla sobre dispositivos técnicos, modos específicos de engarzar nuestros proyectos y el mundo, aunque tales dispositivos no imponen tiránicamente un exclusivo sentido a nuestras acciones ${ }^{11}$. Sintomer analiza el vínculo entre sorteo y democracia, situándolo en un doble registro que tiene la originalidad de ser absolutamente congruente con el pensamiento republicano de las democracias modernas. Primer registro, en el plano de las ideas: una reivindicación de destacados revolucionarios modernos (Sintomer convoca a Mirabeau y John Quincy Adams) fue lograr asambleas parlamentarias que reprodujesen a la sociedad a la que representan. Tal deseo de representación descriptiva no es un exclusivo criterio de democracia, pero sí parece útil para combatir la reproducción

10 Puede leerse al respecto Moreno Pestaña, J. L. (2017): "Foucault, Castoriadis, Rancière y la democracia antigua: ¿qué cabe aprender para una filosofía del sorteo en política?”, Imago crítica, nº 6, 2017, pp. 81-96.

11 Véase las consideraciones de San Martín Sala, J. (1999): Teoría de la cultura, Madrid, Síntesis, pp. 199-216. 
endogámica del personal político. Evidentemente, los representantes políticos actuales ofrecen un espejo muy sesgado de sus sociedades, reclutándose la mayoría entre posiciones sociales privilegiadas. Las instituciones sorteadas pueden servir de contrapeso a esa tendencia, intrínsecamente oligárquica. El segundo registro vincula al sorteo con una innovación técnica indisponible antes del siglo XIX: la noción de muestra representativa. Esta se utiliza constantemente tanto por parte de los institutos de sondeo como por los intentos de mejorar la calidad y la pluralidad de la deliberación sorteando dispositivos de participación. Lo importante de un trabajo como el de Sintomer es que nos enseña a interrogar al sorteo desde nuestros principios políticos y desde las posibilidades que hoy tenemos. Los desafíos que nuestra democracia lanza al sorteo no son para arrumbarlo entre antiguallas periclitadas; son para incentivar nuevas conexiones entre el uso del azar y los ideales democráticos.

Pero antes de aclarar qué pueda ser nuevo, importa y mucho enterarnos de qué pasó ayer. La lectura del mundo clásico, y de su recurso al sorteo, encuentra dos importantísimas aportaciones en el presente monográfico. Una de Liliane López-Rabatel, quien lo aborda desde un ángulo, el de la arqueología, con evidentes paralelos con el de Sintomer, pues ambos nos ayudan a pensar la articulación entre culturas técnicas y políticas, en el caso de López-Rabatel descubriendo rasgos esenciales de la Atenas democrática. Tras realizar un preciso estado de la cuestión acerca de las fuentes de las que disponemos, López-Rabatel nos enseña algo que las fuentes literarias, tan comunes en las humanidades y las ciencias sociales, no son capaces de captar sobre aquella democracia. Un régimen político dedicado a la distribución renovada $-\mathrm{y}$ por ello constante - de cargos públicos no nos ha legado una arquitectura específica — quitando la Pnyx, lugar donde se reunía la asamblea del pueblo de Atenas -, aunque sí algo más modesto pero lleno de significado: un mobiliario. Los instrumentos técnicos para realizar el sorteo incluyen las máquinas y las fichas de identificación con las que los ciudadanos eran distribuidos en su trabajo de renovación de las instituciones. El legado técnico de aquella cultura democrática nos muestra una manera específica de habitar el mundo, en la que el mobiliario de la democracia, sobre el que se sostenían los rituales cívicos de sorteo de cargos, llevaba unido un imaginario político y lazos de sociabilidad muy particulares: el de una ciudad que se integraba por medio de la responsabilización política masiva. Ese imaginario es central para comprender las posibilidades contemporáneas del sorteo. Como explica Sintomer, las empresas de investigación y los gobiernos utilizan constantemente instrumentos para sondear la opinión ciudadana; semejante recurso al azar podría generalizar espacios tendentes a promover la participación política. Para pasar de una a otra utilización la técnica no basta: deben intervenir ideas sobre la democracia y políticas que la encarnen.

La otra historiadora que contribuye a este número se concentra en el sorteo en Roma. Virginie Hollard nos ayuda también a pensar los complejos encajes entre el sorteo y la cultura oligárquica de la república romana. Hollard nos recuerda la clásica distinción entre igualdad aritmética - que reparte a todos por igual-y geométrica - que distribuye según los méritos de cada uno- y nos señala que una interpretación aristocrática de la última sostenía las prácticas políticas en Roma. Este trabajo contribuye a conocer un momento esencial de los conflictos sociales en Roma. En un artículo clásico, Ilsetraut 
Hadot ilustró la estrecha vinculación de las políticas igualitarias de los Gracos con una parte de la escuela estoica (representada por Antípatro de Tarso y Blosio de Cumas), frente a otra parte (ligada a Panecio) tendente a legitimar la aristocracia ${ }^{12}$. Tales compromisos, fundados en el rechazo de la propiedad privada por el primer estoicismo, no se limitaron a Roma, sino que tuvieron efecto en los conflictos sociales de la mismísima Esparta, donde el rey Cleómenes - seguramente inspirado por el estoico Esfero- se enfrentó a la aristocracia de su ciudad-estado. Los conflictos en Roma, tal y como los describe Ilsetraut Hadot, se concentran alrededor del reparto de la tierra. Hollard nos explica que los Gracos pensaron también en la democratización política, específicamente introduciendo el sorteo para transformar la selección de centurias para el voto. Por tanto, la igualdad social iba acompañada de medidas políticas democratizadoras, en las que el sorteo resultaba una apuesta política estratégica. El proyecto llegaría hasta César y, por tanto, su fracaso no cabe atribuirlo en exclusiva a la derrota de los Gracos. Roma siempre mantuvo la tendencia igualadora del sorteo dentro de los límites de las clases altas y nunca equiparó en dignidad política a estas con el pueblo. La visión elitista de la igualdad geométrica restringía pues los efectos políticos más igualitarios del sorteo.

Un salto enorme en el tiempo nos enfrentará de nuevo a los litigios acerca de técnica y participación política, ahora vinculados a la gestión de la carrera científica. Gérard Mauger presenta una polémica acerca de la cualificación de los representantes del Centre National de la Recherche Scientifique. En ella, Mauger concede razón a cada uno de los contendientes: Natalie Heinich criticando la intromisión del capital político si se recurre a elecciones y Christian Topalov rechazando el recurso a la nominación de los representantes por parte de unas elites supuestamente monopolizadoras de la competencia epistémica. Mauger propone reconocer los criterios científicos, eliminando la manipulación facciosa en la elección de representantes, pero sin encomendar la elección a la cúpula administrativa. Para lo cual propone un sistema combinando sorteo y elección y que se inspira en los periodos republicanos de la Florencia de los siglos XIV y XV. Se recurre entonces al sorteo para resolver, en el caso de las ciencias sociales, dilemas comunes a todos los regímenes de expertos y a su legitimidad. Su ejemplo conecta con problemas subrayados por Dimitri Courant en su contribución a propósito de prácticas de designación: la elección (cuestionada por Heinich) o la nominación por una autoridad (rechazada por Topalov), se convierten en objeto de posiciones encontradas porque se sospecha de la calidad de las certificaciones, sobre las cuales se legitima la autoridad tecnocrática. El debate recogido por Mauger se inscribe dentro de la desconfianza en ciertas utilizaciones de la autoridad de la ciencia, una de las causas estructurales que Yves Sintomer identificó como causantes de nuestro renovado interés por las potencialidades políticas del sorteo ${ }^{13}$.

12 Hadot, I. (1970): “Tradition stoïcienne et idées politiques au temps des Gracques", Revue d'Études Latines, $\mathrm{n}^{\circ} 48$.

13 Sintomer, Y. (2011): Petite histoire de l'expérimentation démocratique. Tirage au sort et politique d'Athènes à nos jours, París, La Découverte, pp. 21-22. 


\section{El sorteo y las lecturas intelectuales de la democracia}

Los imaginarios culturales se precisan en relatos intelectuales acerca de la democracia, de su historia y de las posibilidades presentes. Nuestro monográfico introduce dos lecturas específicas acerca de cómo el sorteo nos revela bastante sobre las ideologías intelectuales sobre la democracia.

Dos contribuciones abordan los relatos sobre la democracia desde una perspectiva de sociología del conocimiento. En uno, José Luis Bellón se concentra en el helenismo español durante el franquismo y la transición a la democracia mientras que en el otro Francisco Vázquez interroga a un filósofo de inspiración marxista en los años de la democracia.

Antonio Tovar - falangista acérrimo en la primera hora del franquismo y luego disidente - y Francisco Rodríguez Adrados elaboraron estudios sobre la cultura del siglo V a. C. Ambos son ejemplo de la mistificación del siglo de Pericles, lo cual fue la norma hasta los años 70 del siglo XX. Tovar escribió un estudio sobre Sócrates donde sorteo y misthos (salarios públicos que permiten la participación política) identifican en la democracia una pareja letal: la irracionalidad que desconoce virtud y conocimiento, y la entrega del poder a los menesterosos. Rodríguez Adrados, discípulo de Tovar, incide en ambas dimensiones aunque subrayando la capacidad del caudillo democrático Pericles para contener los excesos radicales de la chusma. No es imposible encontrar homologías entre el Sócrates patriota, crítico del edificio democrático, y la ideología del maestro; tampoco entre la ideología del discípulo y la defensa de una democracia compensada por la moderación de un poder fuerte. Es lo que Bellón sugiere identificando los referentes políticos de ambos helenistas.

A subrayar es que ambos recuerden la conexión entre misthos y sorteo, es decir, entre retribuciones económicas y participación política, entre integración social y estímulo del ejercicio activo de la ciudadanía. Y resulta interesante porque es algo sobre lo que no se entretiene cierta literatura estándar sobre el sorteo, que analiza la débil respuesta ciudadana a los dispositivos sorteados; recordar el componente económico que tuvieron en Atenas no está de más y tal vez ayude a pensar nuevas dimensiones para volver viable el sorteo en nuestro tiempo. Tales dimensiones estuvieron presentes ya en el experimento ateniense, lo que, inspirándose en la obra del Arthur Rosenberg, un helenista del periodo de Weimar, subraya Antoni Domènech. Puede leerse en el artículo que le consagra Francisco Vázquez, un minucioso estudio de las fuentes clásicas presentes en Domènech, primero atraído por el marxismo analítico para posteriormente trabajar desde un pensamiento republicano y socialista. Rosenberg identificó la revolución de Efialtes en el 461 a. C con la toma del poder por el proletariado ateniense ${ }^{14}$. El salario y el sorteo permitieron el autogobierno

14 El capítulo que dedica a analizar la revolución de Efialtes en 461 se titula exactamente así: "El proletariado toma el poder". Rosenberg, A. (2006): Democracia y lucha de clases en la Antigüedad, Barcelona, El Viejo Topo, p. 85. Kojin Karantani ha defendido una formulación aún más radical que ha encontrado una recepción entre las estrellas actuales del marxismo occidental, particularmente Slavoj Zizek. Karatani considera que la elección define la dictadura de la burguesía, mientras que con el sorteo se impondría, al modo de la antigua Atenas, la dictadura del proletariado. La referencia al sorteo del filósofo japonés aparece tras una discusión sobre las relaciones entre Marx y el anarquismo, en la que paradójicamente no aparece la cuestión de los salarios ligados a la socialización política. Pese a lo cual, Karatani analiza con inteligencia el papel de control que el sorteo en Atenas jugaba respecto del aparato de Estado, impidiendo la escisión, siempre criticada por el Marx más libertario, entre sociedad civil y sociedad política. Tras ese análisis, viene su 
efectivo de los trabajadores atenienses y para Domènech ${ }^{15}$ será un ejemplo de la posibilidad de un modelo democrático de masas alternativo a la razón moderna. Esta presenta las preferencias de los agentes políticos como algo dado e inmutable; en contraste el mundo griego considera preferencias capaces, tras el debate con los demás (pero también consigo mismo), de remodelarse reflexivamente. La visión "socialista" del mundo antiguo - perceptible también en la mirada crítica del falangista Tovar - ayuda a Domènech a criticar los republicanismos descuidados respecto de las condiciones sociales de la deliberación y la participación política. Es el modelo, extendidísimo en el mainstream filosófico, de la Grecia dibujada por Hannah Arendt. Apoyada sobre la errónea percepción de Jacob Burckhardt, Arendt nos describe a ciudadanos que deliberan por estar despreocupados del trabajo. Domènech, por el contrario, considera que la democracia ateniense concilió el autogobierno con la participación de las clases populares ${ }^{16}$.

Además, Domènech moviliza el sorteo para pensar los supuestos antropológicos en los que se apoyan las modernas teorías de la elección social. El sorteo en Atenas impedía la creación de coaliciones para obtener un determinado bien público. De ese modo se evitaba la congelación sectaria de las diferencias entre los ciudadanos y se impulsaba el debate acerca de las preferencias de cada uno. En fin, como enfatiza Vázquez, fue la lectura de la democracia antigua la que permitió a Domènech en las dos décadas finales del siglo XX, mantener la conexión entre el ideario socialista y la democracia deliberativa, batiéndose tanto con quienes separaban trabajo y acción política (Arendt pero también Habermas) como con el postmodernismo, al que identificó con el nihilismo oligárquico de los sofistas Calicles y Trasímaco.

propuesta actual: Karatani defiende el uso del sorteo para los puestos más importantes, y no para aquellos como el jurado que sean susceptibles de ser asumidos por todos los ciudadanos. Para lo cual propone un sistema de elección de ternas de candidatos para seleccionar el elegido por sorteo. El objetivo, entre psicoanalítico y anarquista, es evitar la arrogancia del poder, algo que el azar eliminaría, tanto por sus efectos en la conciencia del elegido (podrían ser otros los seleccionados...) como por la imposibilidad de programar las carreras políticas. Se da la paradoja que de este modo se reivindica un sistema análogo al de las elecciones premodernas. La selección de ternas y el sorteo fueron característicos de la elección de los diputados a las Cortes de Cádiz en 1812, algo que dichas Cortes abolirían por sus residuos premodernos. En fin, como explicó Yves Sintomer, a través de su lectura de Hegel, este tipo de elección contradice la idea moderna de que el Estado requiere cualidades que trascienden las competencias de particulares; lo cual restringiría el sorteo a jurados donde solo se trata de decir si algo sucedió o no. Véase el capítulo IV de Karatani, K. (2001): Transcritique. On Kant and Marx, Cambridge, Mass, The MIT Press. Véase Sintomer, Y. (2011): Petite histoire de l'expérimentation démocratique. Tirage au sort et politique d'Athènes à nos jours, París, La Découverte, pp. 120-124.

15 En un artículo reciente Domènech señala cuál fue la rareza de Atenas: la de utilizar los impuestos para formar a los ciudadanos, tanto para las representaciones dramáticas como, cabría añadir, para la participación política. Domènech, A. (2017): “¿Qué hace democrática a una república? Una reflexión sobre el origen de la democracia y algunos malentendidos", Cuba posible, https://cubaposible.com/que-hace-democratica-una-republica/, consultado el 23/06/2017.

16 Véase la definitiva crítica de Ellen Meiksins Wood, en un libro de 1988. Meiksins Wood, E. (2015): Peasantcitizen and Slave. The Foundations of Athenian Democracy, Londres, Verso, Edición Kindle. Pese a su enorme simpatía por el pensamiento de Hannah Arendt, Cornelius Castoriadis planteó en sus cursos sobre Grecia críticas similares. Véase Moreno Pestaña, J. L. (2014): "Pericles en París", Pensamiento. Revista de Investigación e Información Filosófica, [S.1.], v. 70, n. 262, p. 99-119, 


\section{Un espacio de debate sobre los méritos de sorteo y elección}

La democracia ateniense, y el lugar que se le asigne al sorteo en la misma, sirve para singularizar empresas intelectuales en el campo del helenismo y la filosofía contemporánea. El debate entre el sorteo y la elección puede convertirse por derecho propio en centro de debate, refiriéndolo a su lugar en nuestras democracias.

El texto de Yves Sintomer concluye categóricamente en ese punto y procede recordarlo. Existe una necesidad, central en la democracia ateniense, a la que el sorteo no puede responder hoy de la misma manera. Entonces la combinación de sorteo y rotación permitía gobernar y ser gobernado por turnos, introduciendo la política en el centro de la cotidianeidad, hasta producir un mobiliario específico para la democracia que nos describió Liliane López-Rabatel. En el presente no podemos aspirar a reproducir aquel modelo y debemos conformarnos con recuperar otras virtudes del sorteo. La cuestión de las actualizaciones queda abierta. Pueden incluir, lo señala Sebastián Linares, la diversidad cognitiva subrayada por Hélène Landemore en un artículo de referencia. Las personas que participan en tales organismos no han sido formateadas por el cursus honorum que exige la entrada en el campo político y la consecución de un puesto de salida en el disparadero electoral. Para una buena decisión política, las competencias pueden ser igual de fundamentales que la capacidad de reclutar sensibilidades y perspectivas complejas.

Concediéndole ese valor al sorteo, Linares insiste mucho en su incapacidad de garantizar, en ocasiones, competencias que permitan decisiones solventes. Del mismo modo, el sorteo impide el control de los representantes, quienes, ya sea por oportunismo o convicción, tienden, en la lucha por el voto, a alinearse con las posiciones de sus representados. Linares apuesta por un sorteo que complemente y corrija la elección, aportándole una perspectiva amplia y políticamente amateur de la que no debe prescindir ninguna democracia digna de ese nombre. Ahora bien, el lector encontrará en su aportación más reservas que las que nos presenta Dimitri Courant.

Este considera que el sorteo actualiza tres criterios centrales en la democracia: la igualdad (en la elección de representantes o, cuando se ajusta al modelo ateniense, magistrados) ${ }^{17}$, la imparcialidad - que persiste en la institución de nuestros jurados - y la representatividad, siempre que el sorteo ofrezca un número de seleccionados lo suficientemente amplio. Courant responde de modo distinto a una tesis presente en Sebastián Linares. Primero, no considera que la elección tenga ventaja epistémica alguna sobre

17 Cornelius Castoriadis insiste en esa diferencia: el magistrado, comisionado para una función, es revocable, por lo que ha hecho o por cómo lo haya hecho, en todo momento y nada tiene que ver con el representante político moderno. Véase Castoriadis, C. (2008): La cité et les lois. Ce qui fait la Grèce, 2. Séminaires 1983-1984. La création humaine III, París, Seuil, p. 93. Sobre la cuestión de la representación, recomiendo la lectura de las clarificadoras páginas que Antoni Domènech dedica a la relación entre aquel que encarga una tarea (fideicomitente) a otro individuo (fideicomiso). Precisando en el problema del representante político, cuando se piensa desde una perspectiva republicana, aquel que encarga la tarea puede exigir cuentas al fideicomiso. Tal desarrollo aclara bien la idea de por qué un magistrado puede ser un agente para una tarea pero no un representante en el sentido moderno del término. Este, como aclaró Bernard Manin, se basa en un principio de distinción que presume en el representante competencias de las que carece el representado. Véase Domènech, A. (2004): $E l$ eclipse de la fraternidad. Una revisión republicana de la tradición socialista, Barcelona, Crítica, pp. 198-207 y Manin, B. (1995): Principes du gouvernement représentatif, París, Champs, pp. 125-170. 
el sorteo, ya que este puede producir asambleas más competentes que aquella ${ }^{18}$. Mérito específico del texto de Courant es el de ampliar el radio de comparación del sorteo, no limitándose a la elección, sino también a la nominación (o cooptación) o a la certificación (que garantiza un saber). La asamblea sorteada, lejos de arriesgarse a la incompetencia, permite la formación de ciudadanos que deliberan con conocimiento de causa. Courant ilustra su artículo con referencias a su investigación del Consejo Superior de la Función Militar, un organismo del Ministerio de Defensa francés que recurre al sorteo; lo cual nos permite comprender bien hasta qué punto valores del sorteo son necesarios - en esa institución militar, pero también en otros lugares - para evitar el faccionalismo o la arrogancia del representante.

En fin, Courant recoge una preocupación presente en el artículo de Linares, la de que los dispositivos sorteados generen una nueva elite de ciudadanos entrenados en la deliberación. Para evitarlo podríamos incrementar la obligatoriedad de participar en los organismos sorteados, pues la opción de reclutar solo a voluntarios concede primacía a los excesivamente motivados - otra posibilidad, menos compulsiva, es la de un sorteo de todo el cuerpo político que solo a posteriori exige la aceptación.

Asumiendo la verdad de la tesis de Sintomer (el objetivo del autogobierno por turnos según el modelo ateniense es imposible), la propuesta de Dimitri Courant ayuda a enriquecer el debate respecto a cómo incrementar la incorporación de ciudadanos a la participación política. Depende de la obligatoriedad o no de la participación, de la extensión de los dispositivos y de algo que apareció en los estudios de José Luis Bellón y Francisco Vázquez: de cómo se vincula la participación política con la redistribución económica. Arthur Rosenberg, sin duda, sobreactuaba retóricamente cuando identificaba la democracia ateniense con el gobierno proletario - aunque la tesis se encuentra ya en Aristóteles, refiriéndola específicamente al gobierno de los pobres - . Tuvo sin duda el mérito - como Tovar/Adrados o Domènech - de situar el problema de los salarios en el centro del dispositivo de participación antiguo. ¿Podemos pensar en la participación política como instancia de redistribución económica masiva, incluso como elemento de inclusión social? Mucho debería cambiar nuestra idea de integración económica y social por medio del trabajo.

\section{EI sorteo y las prácticas políticas}

Tal cuestión, qué cabe hacer hoy con el sorteo y cómo leer su historia, ocupa dos artículos dedicados a Bernard Manin, autor que con Los principios del gobierno representativo propuso una importante contribución acerca de la distancia de nuestros modernos

18 La atribución de un privilegio epistémico al voto tiene, además de razones, profundas raíces religiosas. Savonarola, en los debates de la segunda república de Florencia a final del siglo XV, se oponía al sorteo porque evitaba el juicio moral del individuo y la iluminación divina; a lo cual quedaba abierto el voto. Dowlen, O. (2008): The Political Potential of Sortition. A Study of the Random Selection of Citizen for Public Office, Exeter, Imprint Academy. Esta dimensión debe integrarse en otra más amplia y que la recubre: la tendencia a preferir procedimientos racionales - que parecen ser conducidos por la inteligencia humana - aun cuando de ellos no salga nada racional. La obra clásica es Elster, J. (1999): Juicios salomónicos. Las limitaciones de la racionalidad como principio de decisión, Barcelona, Gedisa. 
regímenes respecto de la democracia antigua. La obra de Manin tuvo no solo efectos académicos, también políticos incluyendo en estos tanto institucionales como militantes. Sobre los primeros se centra la aportación de Francisco Carballo, que estudia la intervención de Manin en una sesión del parlamento francés. Carballo propone un análisis sociológico de las reacciones al discurso de Manin quien concede al sorteo un lugar, bien que muy limitado, en la reforma de nuestras democracias. El sorteo no solo extraña a los defensores más ortodoxos del statu quo; también y muy señaladamente a quienes alcanzaron, a izquierda o derecha, su posición tras un cursus honorum militante. Carballo teoriza el problema a partir de las aportaciones de Pierre Bourdieu y Daniel Gaxie: el sorteo, concluye, elimina la posibilidad de planificar estratégicamente el acceso a las retribuciones militantes, lo que sin duda tiene algo que enseñarnos respecto de las resistencias que levanta. La aportación de Jorge Costa, a la que me referiré enseguida, incide también en tal dirección.

De la recepción de Manin se ocupa el artículo de Samuel Hayat, en este caso entre los militantes favorables al sorteo. Bernard Manin, se nos explica, se inscribe en una tradición francesa donde la influencia de Montesquieu o Rousseau - quienes dedicaron páginas elogiosas al sorteo-, el interés por la política antigua o la poca fuerza de las teorías más empresariales de la democracia, crearon un propicio caldo de cultivo para un libro como el suyo. A pesar de Manin, los partidarios del sorteo comenzaron a apropiarse de su obra como si fuese un aliado. Pueden encontrarse homologías entre la nebulosa - entre militante y ligada a empresas de participación local- que reivindica el sorteo y la referencia a un instrumento de la democracia antigua, completamente marginado en la moderna: ambos se encuentran fuera del campo político. Y éste, lo demuestran acontecimientos como el referéndum sobre la Constitución europea de 2005, no ha cesado de desacreditarse: ¿cómo no dirigir la mirada a Los principios del gobierno representativo, donde se demuestra de manera solvente que otra definición de la democracia fue posible y estable?

Al margen ya de Bernard Manin y su recepción, Julien Talpin estudia un registro básico del presente político del sorteo, ligado este a otro nombre propio. James Fishkin se inscribió, primero, dentro de los debates sobre democracia y deliberación que concentraron a la filosofía política durante los años ochenta del siglo XX (y a los que también responde, lo recuerdo, la obra de Antoni Domènech estudiada por Francisco Vázquez). Mientras en una primera oleada - los nombres de Jürgen Habermas y Jon Elster pueden simbolizarla - la cuestión fue cómo la deliberación permite buenas decisiones, Fishkin inaugura y se encabalga sobre el deseo de concreción institucional de la deliberación. Los minipúblicos sorteados se convierten tanto en objeto de estudio en ciencia política como en apuesta participativa de las administraciones, fundamentalmente las de nivel local o regional. Buena parte de la eclosión de estudios sobre el sorteo, fundamentalmente con el comienzo del siglo XXI, obedece a tal dinámica, en la que se conjuga la legitimidad del sorteo - en dispositivos de ciencia política experimental - y la existencia de una demanda gubernamental creciente. Surgió a la vez un mercado de la participación, en el que Fishkin se integra muy exitosamente. Talpin realiza un balance mitigado de tal proceso: ha popularizado el sorteo dentro de instancias de escaso poder decisorio y, a 
menudo, recurriendo a organismos sorteados contra los movimientos sociales. Frente a dicha recuperación del sorteo para la docilización popular, Talpin invita a un uso agonístico del sorteo, instrumentalizado por los propios movimientos sociales e integrándolo en dinámicas de autocorrección del aristocratismo militante.

\section{El sorteo en el ciclo político español}

En el paso del movimiento del 15-M a Podemos, el sorteo ocupó un lugar en el ciclo político de debate, tal y como explican Ramón E. Feenstra y Jorge Costa. Las dos contribuciones sitúan el sorteo en una intersección entre el espacio militante y ciudadano, las empresas que pelean por capitalizar la participación y la legitimidad académica. Solo analíticamente cabe distinguir tales esferas pues a menudo se encuentran ocupadas por individuos multiposicionales ${ }^{19}$ que son a la vez empresarios morales de una causa, empresarios políticos de una organización y empresarios de sus propios objetivos económicos. Sin tener claro lo cual, nos despistamos mucho hacia la presente configuración del campo político. Uno de los efectos mayores del neoliberalismo, con su privatización masiva de los servicios públicos, fue exigir que el capitalista - por ejemplo de la participación o, en otro plano, de los servicios sociales - tuviera que disfrazarse de militante o que el militante encontrase, gracias a su información y sus redes de contactos un camino posible para convertirse en capitalista. Siempre existieron lo que Daniel Gaxie describió como retribuciones militantes, pero puede que ahora aprovechen amplios nichos de mercado ligados a los otrora servicios públicos.

Ramón Feenstra reconstruye el debate sobre el sorteo en Podemos y aclara los paradigmas políticos desde los que, muchas veces sin advertirlo (o quizá sin explicitarlo), se articuló su rechazo: es el paradigma de Benjamin Constant, según el cual la libertad de los modernos consiste en ocuparse de los propios asuntos. Tales fueron parte de los argumentos de los dirigentes de Podemos y sus mentores intelectuales; los otros proceden de la visión de la democracia promovida por Joseph Schumpeter: democracia consiste en técnicas electorales de selección de aristocracias. La aportación de Feenstra propone una virtuosa articulación de descripción política y de explicitación teórica.

Fraguado en una experiencia protagonizada en primera persona, Jorge Costa nos ofrece un estudio, tal vez pionero, sobre los intentos de introducir mecanismos de sorteo en uno de los ayuntamientos españoles donde Podemos y sus alianzas alcanzaron el poder. Como el artículo anterior, el de Costa introduce una potente reflexión - en la que se combinan análisis sociológico y teoría política normativa - para explicar los implícitos que dieron sentido a su experiencia. Entre lo mucho relevante de su trabajo quizá cabe recalcar un aspecto: el cambiante valor simbólico del sorteo dependiendo de la trayectoria política de los agentes que lo contemplan como posibilidad. La perspectiva de Costa conecta con buena parte del utillaje intelectual movilizado por Carballo en su análisis.

19 Boltanski, L. (1973): “L'espace multipositionnel. Multiplicité des positions institutionnelles et habitus de classe", Revue française de sociologie, 1, pp. 3-26. 


\section{Referencias}

Boltanski, Luc (1973): “L'espace multipositionnel. Multiplicité des positions institutionnelles et habitus de classe", Revue française de sociologie, 1, pp. 3-26.

Bourdieu, Pierre (2016): Sociologie générale volume 2. Cours au Collège de France 19831986, París, Seuil.

Casals Bergés, Quintín (2012): "Proceso electoral y prosopografía de los diputados de las Cortes extraordinarias de Cádiz (1810-1813)", Revista de historia constitucional, $\mathrm{n}^{\circ} 13$, pp. 193-231.

Collectif Lieux Communs (2011): Le mouvement grec pour la démocratie directe. Le "mouvement de places” 2011 dans la crise mondiale. Première partie, https://collectiflieuxcommuns.fr/IMG/pdf/MouvementGrecDemocratieDierctPremierePartie.pdf, consultado el 22/06/2017.

Delannoi, Gil (2010): Le retour du tirage au sort en politique, París, Fondapol.

Domènech, Antoni (2004): El eclipse de la fraternidad. Una revisión republicana de la tradición socialista, Barcelona, Crítica.

Domínguez, Atilano (1979): "Libertad y democracia en la filosofía política de Spinoza", Revista de estudios políticos, $\mathrm{n}^{\circ} 11, \mathrm{pp}$. 131-156.

Domènech, Antoni (2017): “¿Qué hace democrática a una república? Una reflexión sobre el origen de la democracia y algunos malentendidos", Cuba posible, https://cubaposible. com/que-hace-democratica-una-republica/, consultado el 23/06/2017.

Dowlen, Oliver (2008): The Political Potential of Sortition. A Study of the Random Selection of Citizen for Public Office, Exeter, Imprint Academy.

Goodwin, Barbara (1984): "Justice and the lottery", Political studies, n 32, pp. 190-202.

Hadot, I. (1970): “Tradition stoïcienne et idées politiques au temps des Gracques”, Revue d'Études Latines, $\mathrm{n}^{\circ}$ 48, pp. 137-179.

Headlam, James Wycliffe (1891): Election by lot at Athens, Londres, Cambridge University Press.

Karatani, Kojin (2001): Transcritique. On Kant and Marx, Cambridge, Mass, The MIT Press,

Lorenci, Miguel (2017): “Zizek, un torbellino filosófico”, La Verdad, 30/06/2017, http:// www.laverdad.es/sociedad/zizek-torbellino-filosofico-20170630014949-ntvo.html, consultado el 23/07/2017.

Luccardie, Paul (2014): Democratic Extremism in Theory and Practice. All Power to the People, Nueva York, Routledge.

Manin, Bernard (1995): Principes du gouvernement représentatif, París, Champs.

Mc Cormick, John (2011): Machiavellian Democracy, Cambridge, Mass, Cambridge University Press.

Meiksins Wood, Ellen (2015): Peasant-citizen and Slave. The Foundations of Athenian Democracy, Londres, Verso, Edición Kindle.

Moreno Pestaña, José Luis (2014): "Pericles en París", Pensamiento. Revista de Investigación e Información Filosófica, [S.1.], v. 70, n. 262, p. 99-119.

Moreno Pestaña, José Luis (2017): "Foucault, Castoriadis, Rancière y la democracia antigua: ¿qué cabe aprender para una filosofía del sorteo en política?", Imago crítica, $\mathrm{n}^{\circ} 6$, 2017, pp. 81-96. 
Ober, Josiah (2017): L'enigme grecque, París, La Découverte.

Polo Blanco, Regina (2012): "Los Reyes Católicos y la insaculación en Castilla", Studia historica. Historia Medieval, vol. 17, pp. 137-199.

Rancière, Jacques (2017): En quel temps vivons-nous? Conversation avec Eric Hazan, París, La fabrique éditions.

Rosenberg, Arthur (2006): Democracia y lucha de clases en la Antigüedad, Barcelona, El Viejo Topo.

San Martín Sala, Javier (1999): Teoría de la cultura, Madrid, Síntesis.

Sintomer, Yves (2011): Petite histoire de l'expérimentation démocratique. Tirage au sort et politique d'Athènes à nos jours, París, La Découverte.

Wright, Erik Olin (2014): Construyendo utopías reales, Madrid, Akal.

Zizek, Slavoj (2004): “The parallax view”, New Left Review, n ${ }^{\circ}$ 25, pp. 121-134. 
